\title{
Incidence of Cisplatin Induced Ototoxicity in Adults with Head and Neck Cancer
}

\author{
Joshua B. Greene, ${ }^{1}$ Robert Standring, ${ }^{1}$ Farzan Siddiqui, ${ }^{2}$ and Syed F. Ahsan ${ }^{1}$ \\ ${ }^{1}$ Henry Ford Health System, Department of Otolaryngology-Head \& Neck Surgery, 2799 West Grand Boulevard, \\ Detroit, MI 48202, USA \\ ${ }^{2}$ Henry Ford Health System, Department of Radiation Oncology, 2799 West Grand Boulevard, Detroit, MI 48202, USA
}

Correspondence should be addressed to Joshua B. Greene; jgreene2@hfhs.org

Received 26 August 2015; Accepted 2 November 2015

Academic Editor: Giuseppe Mercante

Copyright (C) 2015 Joshua B. Greene et al. This is an open access article distributed under the Creative Commons Attribution License, which permits unrestricted use, distribution, and reproduction in any medium, provided the original work is properly cited.

\begin{abstract}
Objective. To elucidate the incidence of cisplatin induced ototoxicity in adult patients, with a focus on an adult population. Study Design. IRB approved retrospective study. Methods. The charts of patients who underwent cisplatin therapy from 1995 to present were reviewed. Inclusion criteria were (1) cisplatin as the primary chemotherapeutic agent and (2) hearing evaluation performed prior to and after treatment. Audiometric thresholds were measured by presenting pure-tone stimuli at 0.25 to $10.0 \mathrm{kHz}$. Criteria for hearing loss were based on the Chang criteria. Cochlear radiation doses were also calculated in patients with primary tumors in their head and neck or brain. Results. There were 1565 patients that had undergone therapy with cisplatin from 1995 to 2014, which 30 met inclusion criteria. Eight were patients treated for head and neck or brain cancer. Evaluation with ANOVA testing identified statistically significant decline in audiometric scores for WRS and pure tone frequencies 500, 2000, 4000,6000, and $8000 \mathrm{~Hz}$ in the right ear. Overall, hearing loss was noted with $63 \%$ incidence and in patients who received radiation to their cochlea and cisplatin. Conclusion. The incidence of cisplatin induced ototoxicity was significant and even more prevalent in those patients receiving both cisplatin and radiation to their cochlea.
\end{abstract}

\section{Introduction}

Cisplatin based treatment regimens have long been the gold standard in the treatment of various soft tissue neoplasms, specifically ovarian, testicular, cervical, non-small cell lung, bladder, and head and neck. Although several mechanisms have been proposed, it has generally been believed to work through depletion of the tumors' endogenous antioxidant system and activate its own apoptosis [1]. Despite the many beneficial features of cisplatin, serious side effects are nephrotoxicity, neurotoxicity, and ototoxicity. In regard to ototoxicity, it is believed that cisplatin selectively damages the outer hair cells within the organ of Corti, spiral ganglion cells and cells within the stria vascularis $[2,3]$. Ototoxicity can occur anytime from hours to days after treatment. The loss is considered permanent and dose related and cumulative and affects the higher frequencies [4]. The hearing loss can progress for up to 2 years in $15-20 \%$ of patients [5].
Recent studies have suggested the importance of measuring pretreatment hearing thresholds in predicting the outcome following therapy with cisplatin. Brock et al. designed one of the first classification schemes, created to classify pediatric patients into subgroups of hearing loss after receiving cisplatin [6]. This was further modified to yield the Chang classification, which was more sensitive at detecting hearing loss than its predecessor $[7,8]$. Johnson et al. subsequently showed that the Chang classification scheme was a useful tool in adults to show how pretreatment hearing thresholds may predict response to cisplatin treatment [9].

Despite all of these advancements in prediction methods and classification schemes, there has been little documentation on the frequency of hearing loss in adults undergoing cisplatin therapy. To our knowledge, there has been no reported incidence of cisplatin based hearing loss in the head and neck cancer population. Within the pediatric population, there has been report of as much as $30 \%$ clinically significant 
TABle 1: Patient demographics.

\begin{tabular}{lc}
\hline Age & 17-81 (average 59.2) years \\
\hline Sex & Male 14 (47\%) \\
& Female 16 (53\%) \\
\hline & Lung 13 (44\%) \\
Tumor location & Head/neck \& brain $8(27 \%)$ \\
& Kidney/bladder $5(16 \%)$ \\
& Uterus/ovarian 3 $(10 \%)$ \\
Unknown $1(3 \%)$
\end{tabular}

hearing loss [10]. In head and neck cancer, chemotherapy is also combined with radiation for advanced tumors which may work synergistically with cisplatin to increase the risk of hearing loss. There have been reports that cochlear radiation doses greater than $45 \mathrm{~Gy}$ may cause hearing loss [11, 12]. Therefore, the goals of our study were to determine a relative incidence rate of cisplatin induced ototoxicity in the adult population and to specifically examine rates in head and neck cancer patients. It is our hope that this data will help otolaryngologists, oncologists, and radiation-oncologists realize the importance of pre- and post-cisplatin therapy audiologic testing.

\section{Patients and Methods}

Approval was obtained from our hospital institutional review board for a retrospective chart review. A total of 1565 medical records from 1995 to 2014 were reviewed for all patients who have received cisplatin. Inclusion criteria were (1) that cisplatin was used as the primary chemotherapeutic agent and (2) that hearing evaluation must have been performed prior to and after cisplatin treatment The most common reason for exclusion was lack of either pretreatment or posttreatment hearing evaluation. Based on these criteria, 30 subjects were included in the study (Table 1).

Baseline hearing thresholds were assessed prior to the start of cisplatin. Audiometric hearing thresholds were measured by presenting pure-tone stimuli at $0.25,0.5,1.0,2.0,4.0$, $6.0,8.0$, and $10.0 \mathrm{kHz}$. The criteria for classification of hearing loss were based on the results from audiograms. Severity of hearing loss was graded according to the Chang criteria, that is, designated and validated specifically for cisplatin induced hearing loss (Table 2).

In those patients with tumor locations in the head/neck and brain, who received radiation in addition to cisplatin, their cochlear radiation doses were examined.

\section{Results}

Over a nineteen-year span from 1995 to 2014, 1565 patients underwent chemotherapy with cisplatin. Two hundred and
TABLE 2: Chang classification of cisplatin induced hearing loss [7].

\begin{tabular}{lc}
\hline Grade & Sensorineural hearing threshold $(\mathrm{db} \mathrm{HL})$ \\
\hline 0 & $\leq 20 \mathrm{~dB}$ at 1,2 , and $4 \mathrm{kHz}$ \\
$\mathrm{la}$ & $\geq 40 \mathrm{~dB}$ at any frequency $6-12 \mathrm{kHz}$ \\
$\mathrm{lb}$ & $>20$ and $>40 \mathrm{~dB}$ at $4 \mathrm{kHz}$ \\
$2 \mathrm{a}$ & $\geq 40 \mathrm{~dB}$ at $4 \mathrm{kHz}$ and above \\
$2 \mathrm{~b}$ & $>20$ and $<40 \mathrm{~dB}$ at any frequency below $4 \mathrm{kHz}$ \\
3 & $\geq 40 \mathrm{~dB}$ at 2 or $3 \mathrm{kHz}$ and above \\
4 & $\geq 40 \mathrm{~dB}$ at $1 \mathrm{kHz}$ and above \\
\hline
\end{tabular}

TABLE 3: Pretreatment versus posttreatment hearing examination using the Chang criteria. Worsening posttreatment hearing is written in bold.

\begin{tabular}{|c|c|}
\hline Pretreatment (right/left) & Posttreatment (right/left) \\
\hline $2 a / 2 b$ & $2 \mathrm{~b} / 2 \mathrm{~b}$ \\
\hline $1 \mathrm{a} / 2 \mathrm{~b}$ & $1 \mathrm{a} / 2 \mathrm{~b}$ \\
\hline $3 / 3$ & $3 / 3$ \\
\hline $0 / 4$ & $\mathbf{l a} / 4$ \\
\hline $4 / 4$ & $4 / 4$ \\
\hline $2 \mathrm{~b} / 1 \mathrm{a}$ & $4 / 1 \mathrm{a}$ \\
\hline $2 b / 2 b$ & $2 \mathrm{~b} / 2 \mathrm{~b}$ \\
\hline $0 / 0$ & $0 / 0$ \\
\hline $0 / 0$ & $1 b / 0$ \\
\hline $0 / 0$ & $0 / 0$ \\
\hline $4 / 4$ & $4 / 4$ \\
\hline $3 / 4$ & $3 / 4$ \\
\hline $2 b / 2 b$ & $3 / 3$ \\
\hline $2 b / 2 a$ & $2 b / 2 b$ \\
\hline $3 / 3$ & $4 / 3$ \\
\hline $4 / 2 b$ & $4 / 3$ \\
\hline $2 a / 2 a$ & $2 a / 2 b$ \\
\hline $0 / 0$ & $1 \mathbf{a} / \mathbf{1 a}$ \\
\hline $0 / 1 \mathrm{a}$ & $\mathbf{1 b} / \mathbf{1 b}$ \\
\hline $0 / 4$ & $1 b / 4$ \\
\hline $2 b / 2 b$ & $3 / 4$ \\
\hline $2 b / 2 b$ & $2 \mathrm{~b} / 2 \mathrm{~b}$ \\
\hline $4 / 4$ & $4 / 4$ \\
\hline $1 b / 2 b$ & $3 / 2 b$ \\
\hline $2 b / 2 a$ & $2 b / 2 b$ \\
\hline $1 \mathrm{a} / 1 \mathrm{a}$ & $2 b / 2 b$ \\
\hline $2 b / 3$ & $2 \mathrm{~b} / 4$ \\
\hline $4 / 2 b$ & $4 / 4$ \\
\hline $4 / 4$ & $4 / 4$ \\
\hline $2 a / 1 b$ & $2 a / 2 b$ \\
\hline
\end{tabular}

three patients underwent audiometric testing before or after therapy. Only 30 of those patients had appropriate pre- and posttherapy hearing tests to be included in this study. Eight of the 30 patients were treated for head and neck or brain cancer. Twelve patients were treated for lung cancer, seven were treated for bladder/uterus or pelvic cancer, one was treated for ovarian cancer, and 2 were treated for unknown primaries. Table 1 demonstrates the breakdown of cancer type 
TABLE 4: Cochlear radiation doses and associated hearing examination classified with the Chang criteria.

\begin{tabular}{lccccc}
\hline $\begin{array}{l}\text { Cochlear max } \\
\text { dose (Gy), left }\end{array}$ & $\begin{array}{c}\text { Cochlear mean } \\
\text { dose (Gy), left }\end{array}$ & $\begin{array}{c}\text { Left pretreat- } \\
\text { ment/posttreatment Chang } \\
\text { classification }\end{array}$ & $\begin{array}{c}\text { Cochlear max dose } \\
\text { (Gy), right }\end{array}$ & $\begin{array}{c}\text { Cochlear mean } \\
\text { dose (Gy), right }\end{array}$ & $\begin{array}{c}\text { Right pretreat- } \\
\text { ment/posttreatment Chang } \\
\text { classification }\end{array}$ \\
\hline 53.9 & 42.2 & $4 / 4$ & 48.6 & 39.5 & $0 / 1 \mathrm{a}$ \\
6.3 & 2.9 & $1 \mathrm{a} / \mathrm{la}$ & 14.1 & 9 & $2 \mathrm{~b} / 4$ \\
3.2 & 2.2 & $4 / 4$ & 3 & 3.3 & 2.1 \\
2.7 & 2.4 & $2 \mathrm{a} / 2 \mathrm{~b}$ & 64.8 & 46.8 & $2 \mathrm{~b} / 2 \mathrm{~b}$ \\
65.3 & 47.6 & $4 / 4$ & 30 & 30 & $0 / 1 \mathrm{a}$ \\
30 & 30 & $2 \mathrm{~b} / 4$ & & & $2 \mathrm{~b} / 3$ \\
\hline
\end{tabular}

TABLE 5: ANOVA analysis of changes in posttreatment hearing evaluation; highlighted values represent statistical significant worsening values.

\begin{tabular}{lcc}
\hline Variable & Ear & $p$ value \\
\hline \multirow{2}{*}{ SRT } & R & 0.125 \\
& L & 0.395 \\
\hline \multirow{2}{*}{ WRS } & R & $\mathbf{0 . 0 0 4}$ \\
& L & 0.755 \\
\hline \multirow{2}{*}{$250 \mathrm{~Hz}$} & $\mathrm{R}$ & 0.606 \\
& $\mathrm{~L}$ & 0.176 \\
\hline \multirow{2}{*}{$500 \mathrm{~Hz}$} & $\mathrm{R}$ & $\mathbf{0 . 0 4 9}$ \\
& $\mathrm{L}$ & 0.465 \\
\hline \multirow{2}{*}{$1000 \mathrm{~Hz}$} & $\mathrm{R}$ & 0.165 \\
& $\mathrm{~L}$ & 0.294 \\
\hline \multirow{2}{*}{$2000 \mathrm{~Hz}$} & $\mathrm{R}$ & $\mathbf{0 . 0 1 3}$ \\
& $\mathrm{L}$ & 0.614 \\
\hline \multirow{2}{*}{$4000 \mathrm{~Hz}$} & $\mathrm{R}$ & $\mathbf{0 . 0 0 2}$ \\
\hline \multirow{2}{*}{$6000 \mathrm{~Hz}$} & $\mathrm{~L}$ & 0.202 \\
\hline \multirow{2}{*}{$8000 \mathrm{~Hz}$} & $\mathrm{R}$ & $\mathbf{0 . 0 0 1}$ \\
& $\mathrm{L}$ & 0.191 \\
\hline
\end{tabular}

and highlights other patient factors in treatment. Nineteen out of the thirty patients $(63 \%)$ had some hearing loss in either one or both ears based on the Chang criteria (Table 3). The mean cisplatin dose for each of the 30 patients was 55$260 \mathrm{mg} / \mathrm{m}^{2}$ (average: $148 \mathrm{mg} / \mathrm{m}^{2}$ ). The average cisplatin dose in the eight head/neck/brain patients was $113.3 \mathrm{mg} / \mathrm{m}^{2}$ (range $\left.50-190 \mathrm{mg} / \mathrm{m}^{2}\right)$. Of the eight patients with tumors located in the head/neck and brain, six received radiation in addition to cisplatin. The amount of radiation (max and mean) given to the cochlea is highlighted in Table 4 . Based on the Change criteria, there was hearing loss in 5/6 (83.3\%) of the head/neck and brain patients who received both cisplatin and radiation to their cochlea.

An analysis of variance (ANOVA) was used for the repeated measures. Each analysis had a factor for pre- and posttreatment for each ear (Table 5). Using a significance factor of 0.05 , there was a significant decline in audiometric scores for WRS and pure-tone frequencies 500, 2000, 4000, 6000 , and $8000 \mathrm{~Hz}$ in the right ear. The hearing at $250 \mathrm{~Hz}$ and the change in SRT were decreased after treatment but did not reach significance.

Multiple other factors were compared in the pre- and posttreatment analysis. Five out of 30 patients admitted to having vertigo symptoms prior to treatment while 6 additional patients developed vertigo during therapy. One patient's vertigo resolved during treatment. Half of the patients complained of tinnitus prior to therapy, while 5 patients developed tinnitus during therapy. One patient's tinnitus improved during the duration of therapy.

\section{Discussion}

This study demonstrates that there was $63 \%$ incidence of hearing loss after cisplatin therapy in adults. Furthermore, it demonstrates $62.5 \%$ incidence of hearing loss in patients with head and neck cancer that had concomitant radiation therapy. This result is similar to what Chen et al. found in 2006 when they showed that a cochlear radiation dose greater than $48 \mathrm{~Gy}$ was noted to have significantly increased risk of ototoxicity [13]. The difference seen in the current paper is that only two out of the eight of the patients had a cochlear radiation dose greater than $48 \mathrm{~Gy}$ and both of them had post-cisplatin treatment hearing loss. The value of this current study was highlighting the inadequate audiologic testing prior to and after cisplatin therapy. Thirty patients out of 1565 (1.9\%) had appropriate testing with both pre- and post-audiologic testing.

Cisplatin therapy is known to cause hearing loss due to a variety of factors. The charged platinum molecule is highly reactive and integrates into nucleophilic groups (G-C rich) in DNA. This causes intrastrand and interstrand DNA crosslinks that result in apoptosis and cell-growth inhibition. It is thought to target the organ of Corti, especially the outer hair cells, the type 1 spiral ganglion cells causing detachment of the myelin sheaths as well as the stria vascularis causing cell rupture in that area. Cisplatin also binds to sulhydryl groups and depletes copper, selenium, glutathione, and NADPH, increasing reactive oxygen species and oxidative stress [14].

Patients with head and neck cancer are at an increased risk for ototoxicity for many factors including concomitant cochlear radiation, disruption of vascular flow, and increased cisplatin doses. Head and neck patients need to have proper pretreatment and peritreatment audiologic testing to monitor for hearing loss. If patients demonstrate evidence of hearing 
loss, then their treatment can be modified or terminated. Our institution had dismal $1.9 \%$ of patients that had adequate preand posttreatment audiologic testing. During the study, our institution realized this inadequacy and initiated a protocol for all patients undergoing cisplatin therapy. This included high frequency audiograms up to $12 \mathrm{kHz}$ and DPOAEs on all patients prior to cisplatin therapy, directly after treatment and at six months after treatment.

\section{Conclusion}

In patients receiving platinum base chemotherapy and/or radiation to the cochlea, hearing loss remains a common side effect of the treatment. Although it has been found with high incidence, many institutions (including the present authors' one) have lacked ototoxicity protocol for these patients. New large scale studies must be conducted to evaluate for true incidence of hearing loss, in order to get to a point of earlier identification and prevention of this outcome.

\section{Conflict of Interests}

The authors declare that there is no conflict of interests regarding the publication of this paper.

\section{References}

[1] R. Ravi, S. M. Somani, and L. P. Rybak, "Mechanism of cisplatin ototoxicity: antioxidant system," Pharmacology and Toxicology, vol. 76, no. 6, pp. 386-394, 1995.

[2] M. W. M. Van Ruijven, J. C. M. J. De Groot, S. F. L. Klis, and G. F. Smoorenburg, "The cochlear targets of cisplatin: an electrophysiological and morphological time-sequence study," Hearing Research, vol. 205, no. 1-2, pp. 241-248, 2005.

[3] S. Kohn, M. Fradis, H. Pratt et al., "Cisplatin ototoxicity in guinea pigs with special reference to toxic effects in the stria vascularis," Laryngoscope, vol. 98, no. 8, part 1, pp. 865-871, 1988.

[4] C. Bokemeyer, C. C. Berger, J. T. Hartmann et al., "Analysis of risk factors for cisplatin-induced ototoxicity in patients with testicular cancer," British Journal of Cancer, vol. 77, no. 8, pp. 1355-1362, 1998.

[5] S. C. Dutton, M. Neault, A. E. Billett et al., "Progressive ototoxicity after combined modality treatment of medulloblastoma," in Proceedings of the 38th Annual ASTRO Meeting, 2000.

[6] P. R. Brock, S. C. Bellman, E. C. Yeomans, C. R. Pinkerton, and J. Pritchard, "Cisplatin ototoxicity in children: a practical grading system," Medical and Pediatric Oncology, vol. 19, no. 4, pp. 295300, 1991

[7] K. W. Chang and N. Chinosornvatana, "Practical grading system for evaluating cisplatin ototoxicity in children," Journal of Clinical Oncology, vol. 28, no. 10, pp. 1788-1795, 2010.

[8] K. W. Chang, "Clinically accurate assessment and grading of ototoxicity," Laryngoscope, vol. 121, no. 12, pp. 2649-2657, 2011.

[9] A. Johnson, S. Tarima, S. Wong, D. R. Friedland, and C. L. Runge, "Statistical model for prediction of hearing loss in patients receiving cisplatin chemotherapy," JAMA Otolaryngology-Head and Neck Surgery, vol. 139, no. 3, pp. 256-264, 2013.
[10] E. Peleva, N. Emami, M. Alzahrani et al., "Incidence of platinum-induced ototoxicity in pediatric patients in Quebec," Pediatric blood \& cancer, vol. 61, no. 11, pp. 2012-2017, 2014.

[11] N. Bhandare, P. J. Antonelli, C. G. Morris, R. S. Malayapa, and W. M. Mendenhall, "Ototoxicity after radiotherapy for head and neck tumors," International Journal of Radiation Oncology Biology Physics, vol. 67, no. 2, pp. 469-479, 2007.

[12] W. C. Chen, C. T. Liao, H. C. Tsai et al., "Radiation-induced hearing impairment in patients treated for malignant parotid tumor," Annals of Otology, Rhinology \& Laryngology, vol. 108, no. 12, pp. 1159-1164, 1999.

[13] W. C. Chen, A. Jackson, A. S. Budnick et al., "Sensorineural hearing loss in combined modality treatment of nasopharyngeal carcinoma," Cancer, vol. 106, no. 4, pp. 820-829, 2006.

[14] L. P. Rybak, C. A. Whitworth, D. Mukherjea, and V. Ramkumar, "Mechanisms of cisplatin-induced ototoxicity and prevention," Hearing Research, vol. 226, no. 1-2, pp. 157-167, 2007. 


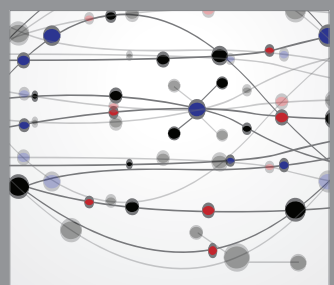

The Scientific World Journal
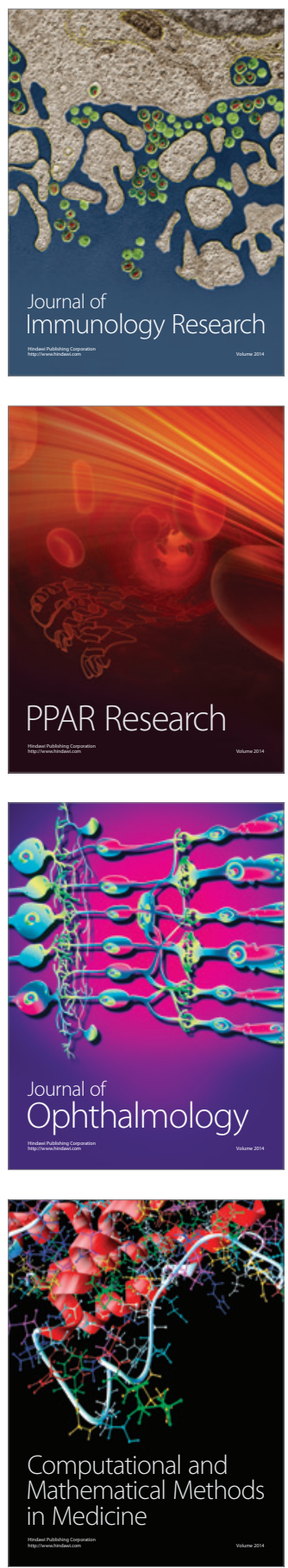

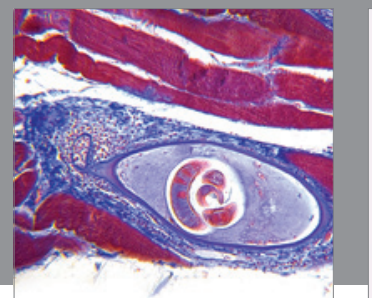

Gastroenterology

Research and Practice
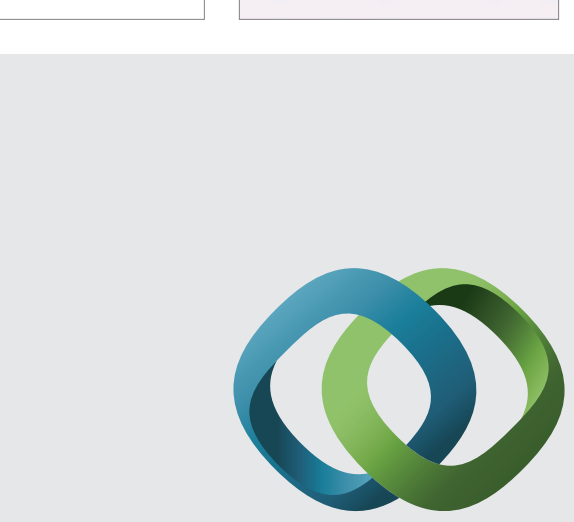

\section{Hindawi}

Submit your manuscripts at

http://www.hindawi.com
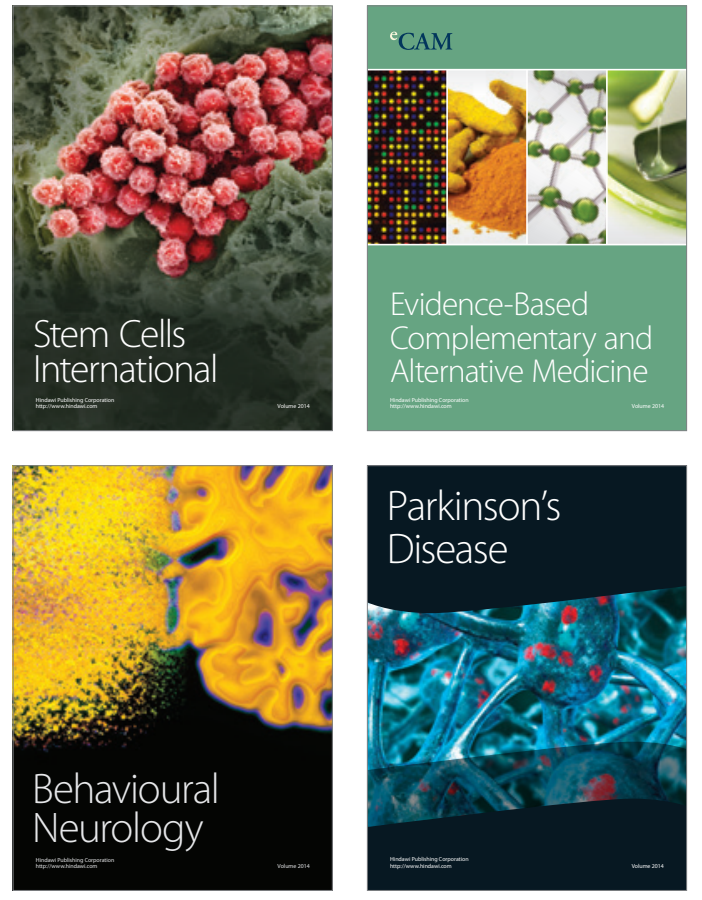
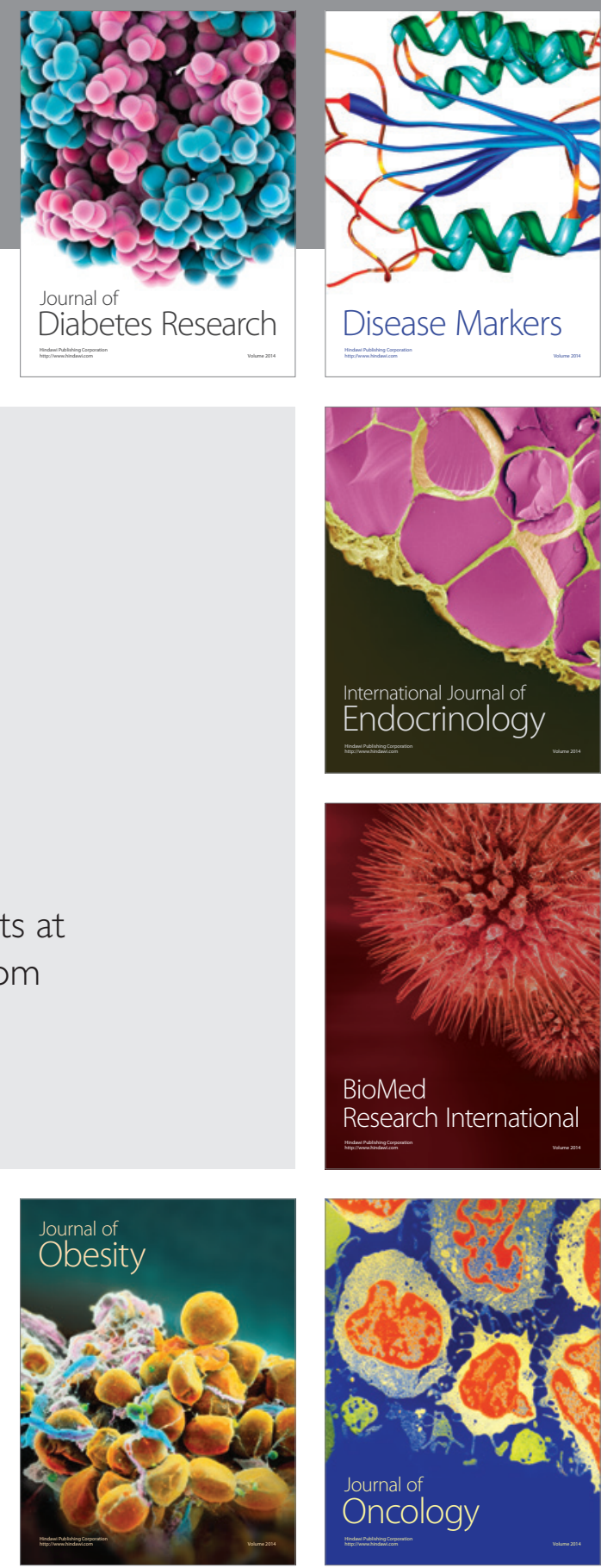

Disease Markers
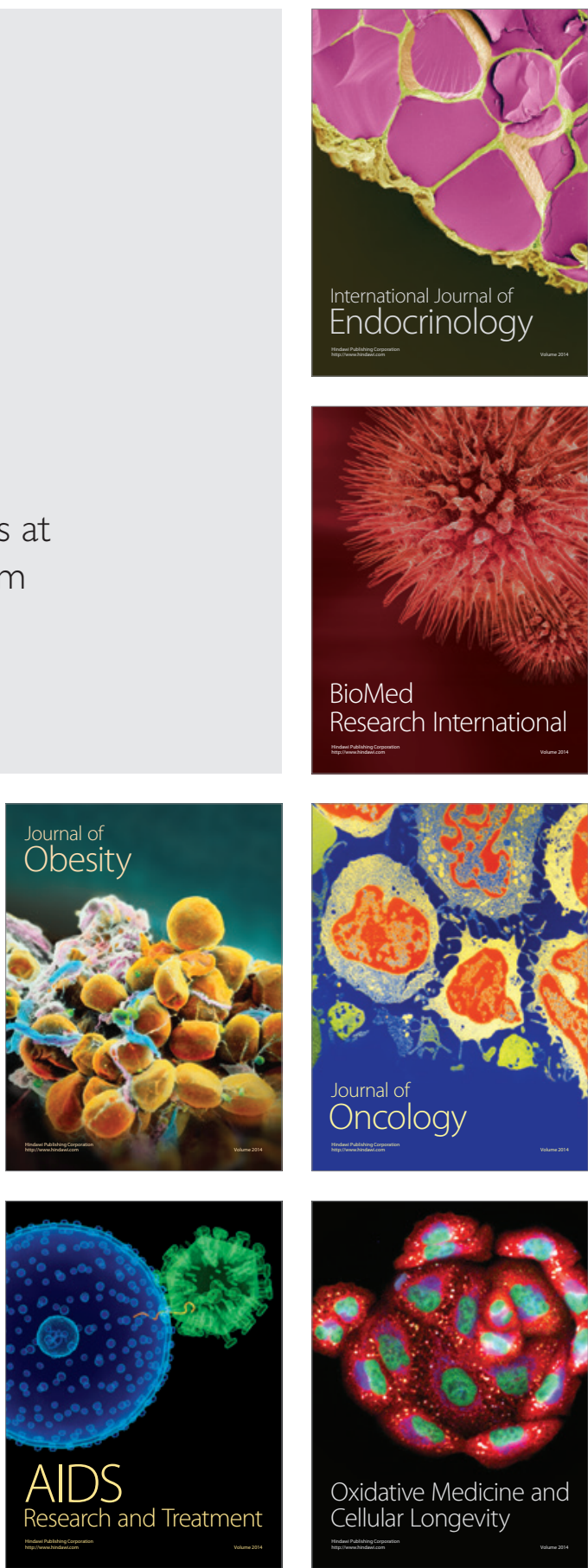